\title{
FONTES E PROPORÇÃO DE MATERIAL ORGÂNICO PARA A PRODUÇÃO DE MUDAS DE CAFEEIRO EM TUBETES
}

\author{
Sources and proportions of organic components for production of coffee tree seedling \\ (Coffea arabica L.) in small plastic containers
}

\author{
Ricardo Dias ${ }^{1}$, Benjamim de Melo ${ }^{2}$, Marina de Alcântara Rufino ${ }^{3}$, \\ Daniel Lima Silveira ${ }^{4}$, Tâmara Prado de Morais ${ }^{5}$, Denise Garcia de Santana ${ }^{6}$
}

\begin{abstract}
RESUMO
Neste trabalho, objetivou-se avaliar a qualidade das mudas de cafeeiro (Coffea arabica L.) produzidas em tubetes com substrato artificial suplementado com fontes de material orgânico em diferentes proporções. O experimento foi conduzido sob delineamento experimental de blocos casualizados em esquema fatorial 3 × 6 , com quatro repetições em parcelas formadas por seis tubetes. O primeiro fator correspondeu às fontes de material orgânico (esterco bovino, húmus de minhoca e cama de peru) e o segundo, suas proporções $\left(0,20,40,60,80\right.$ e 100\%) no substrato artificial (BioPlant-café) fertilizado com osmocote ${ }^{\circ}$ (NPK 15-09-12). As características avaliadas foram: altura da muda, diâmetro de caule, número de pares de folhas, área foliar e massa seca da parte aérea e do sistema radicular. Pode-se concluir que o húmus de minhoca adicionado ao substrato artificial na proporção de $80 \%$ ou em uso exclusivo (100\%) aumentou a área foliar das mudas de cafeeiro e, como conseqüência proporcionou um maior acúmulo de massa seca da parte aérea. O uso de esterco bovino (acima de 30\%) e a cama de peru não alterou ou reduziu as características vegetativas das mudas de cafeeiro (altura da muda, diâmetro de caule, número de pares de folhas e área foliar) e diminuiu o acúmulo de massa seca.
\end{abstract}

Termos para indexação: Adubação orgânica, Coffea arabica, substrato.

\begin{abstract}
This work aimed to evaluate the quality of coffee seedlings (Coffea arabica L.) produced in small plastic containers with artificial substrate supplemented with sources of organic components in different proportions. The experiment was carried out using the randomized block design, in a $3 \times 6$ factorial structure, with four replications in plots composed of small plastic containers. The first factor corresponded to the sources (cattle manure, earthworm casting, and turkey manure) and the second to the proportions ( 0 , 20, 40, 60, 80, and 100\%) in the artificial substrate (BioPlant-café ${ }^{\circ}$ ) fertilized with osmocote ${ }^{\circledR}$ (NPK 15-09-12). The characteristics evaluated were: seedling height, seedling stem diameter, number of pair of leaves, leaf area, shoot dry matter and root system dry matter. This work concluded that the earthworm casting added to the artificial substrate in proportion of $80 \%$ or by itself (100\%) increases the leaf area of coffee seedlings and, as a consequence it provides a higher accumulation of dry matter in the shoot. The use of cattle (up to 30\%) and turkey manure did not modify or reduced seedling height, seedling stem diameter, number of pair of leaves as well as the leaf area and decreased the accumulation of dry matter.
\end{abstract}

Index terms: Organic fertilization, Coffea arabica, substrate.

(Recebido em 23 de novembro de 2007 e aprovado em 27 de maio de 2008)

\section{INTRODUÇÃO}

O café é um dos principais produtos agrícolas produzidos no mundo, sendo cultivado nos mais diversos tipos de solo e de clima, com os mais diferentes métodos de plantio. No Brasil, a cultura do cafeeiro sempre ocupou posição de destaque, proporcionando importante função social como geradora de empregos e fixadora da população na zona rural, além da sua participação na economia do País em toda a história da sociedade brasileira (POZZA et al., 2001). Por ser uma cultura perene, requer cuidados especiais para implantação, sendo a produção de mudas uma das principais fases da cultura (CARVALHO, 1978). Sua tecnologia de produção vem sendo alterada nos últimos anos, com pesquisas para determinação do tipo de recipiente, substrato, tempo e manejo das adubações e de

${ }^{1}$ Engenheiro Agrônomo, Mestre - Escola Agrotécnica Federal de Uberlândia/EAFUDI - Fazenda Sobradinho - Cx. P. 592 - $38400-974$ - Uberlândia, MG eafudi@eafudi.gov.br

²Engenheiro Agrônomo, Doutor - Instituto de Ciências Agrárias/ICIAG - Universidade Federal de Uberlândia/UFU - Avenida João Naves de Ávila, 2121 Cx.P. 593 - 38400-902 - Uberlândia, MG - benjamim@umuarama.ufu.br

${ }^{3}$ Engenheira Agrônoma, Avenida Carneiro Leão, 65 - 14ํㅡㄹ Andar - Sala 1409 a 1412 - Zona 1 - 87014-010 - Maringá, PR - marina_rufino@hotmail.com ${ }^{4}$ Engenheiro Agrônomo, Cargill Agrícola S/A - Rodovia Ilhéus-Uruçuca, Km 08 - Setor Industrial - 45658-335 - Ilhéus, BA - dlsjomps@gmail.com ${ }^{5}$ Graduanda em Agronomia, Instituto de Ciências Agrárias/ICIAG - Universidade Federal de Uberlândia/UFU - Avenida Amazonas, s/n - Umuarama 38400-902 - Uberlândia, MG - morais prado@netsite.com.br

${ }^{6}$ Engenheira Agrônoma, Doutora - Instituto de Ciências Agrárias/ICIAG - Universidade Federal de Uberlândia/UFU - Avenida João Naves de Ávila, 2121 Cx.P. 593 - 38400-902 - Uberlândia, MG - dgsantana@umuarama.ufu.br

Ciênc. agrotec., Lavras, v. 33, n. 3, p. 758-764, maio/jun., 2009 
irrigação ideais para produção de mudas com qualidade. Sem dúvida, mudas sadias e bem desenvolvidas constituem um dos fatores básicos para o sucesso da formação de novas lavouras (GUIMARÃES et al., 1989).

O desenvolvimento de novas formulações de substrato está disponível, especialmente para a produção de mudas em tubetes (MELLO, 1999). O tubete apresenta várias vantagens em relação aos sacos de polietileno, como a facilidade operacional, redução de mão-de-obra e da área do viveiro e redução no volume de substrato (FREITAS et al., 2006). Fagundes \& Fialho (1986) ressaltam outras vantagens como uma formação de sistema radicular sem enovelamento e um crescimento inicial acelerado das mudas. Por outro lado, o pequeno volume de substrato exige a aplicação de doses concentradas de nutrientes (NEVES et al., 1990). Os aspectos nutricionais não são as únicas exigências a serem atendidas no processo de formação da muda. O substrato deve reunir características físicas e químicas exigidas pela planta (CUNHA et al., 2006; GONÇALVES \& POGGIANI, 1996; PASQUAL et al., 2001), além de proporcionar maior facilidade para a retirada da muda do tubete por ocasião do plantio no campo (ANDRADE NETO et al., 1999). Além disso, deve ser considerado o custo individual em relação ao custo final da muda. A matéria-prima deverá ser de baixo custo, fácil utilização, longa durabilidade e renovável (CARRIJO et al., 2004; FONSECA, 2001).

Os substratos são constituídos pelas frações química, física e biológica, sendo a proporção e a qualidade de cada uma dessas frações determinantes dos nutrientes e das características físicas favoráveis à planta. Para agregar estas frações, alguns substratos têm sido lançados no mercado, especialmente para a produção de mudas de cafeeiro, com características voltadas à sua fisiologia (MELLO, 1999). Substratos comerciais utilizados para a formação de mudas de espécies arbóreas, incluindo o cafeeiro, normalmente possuem boas características físicas, mas necessitam de complementação de nutrientes via solução química (LOPES, 1996) ou adubos sólidos, de preferência, de liberação gradual.

Antes da produção de mudas de cafeeiro por tubetes, a mistura mais usual era formada por solo (70\%) com esterco bovino (30\%), enriquecida com adubos químicos e acondicionada em saquinhos plásticos (polietileno). Informações a respeito de substratos para a produção de mudas de cafeeiro em tubetes ainda são escassas e o que se conhece foi determinado para espécies florestais (ANDRADE NETO et al., 1999). O húmus de minhoca ou vermicomposto é um material que vem sendo estudado na constituição de substratos, sendo, em média,
$70 \%$ mais rico em nutrientes que os húmus convencionais. Sua riqueza em bactérias e outros microorganismos facilita a assimilação dos nutrientes pelas raízes, apresentando, ainda, a vantagem de possuir pH próximo de 7,0 (ANDRADE NETO et al., 1999). Ainda segundo estes autores, em mudas de cafeeiro, o esterco bovino na proporção de $80 \%$, adubado com osmocote $§$, garante uma maior altura de planta, de massa seca de raízes e de parte aérea. Diante do exposto, esse trabalho visa a avaliar a qualidade das mudas de cafeeiro (Coffea arabica L.) produzidas em tubetes com substrato artificial suplementado com fontes de material orgânico em diferentes proporções.

\section{MATERIAL E MÉTODOS}

O experimento foi instalado e conduzido no Viveiro de Produção de Mudas Brasil Cerrado, localizado no km 37,5 da BR 050, no município de Araguari-MG, no período de maio de 2005 a abril de 2006. Sementes de cafeeiro (Coffea arabica L.) da cultivar Acaiá Cerrado linhagem MG-1474 foram obtidas no Setor de Cafeicultura da Universidade Federal de Uberlândia, situada na Fazenda Experimental do Glória. Os frutos foram colhidos de forma seletiva no estádio cereja e passaram por processos de seleção e despolpamento. As sementes secaram à sombra até atingirem $12 \%$ de umidade, quando foram eliminadas aquelas mal formadas. A semeadura foi realizada em sementeira, utilizando-se areia lavada como substrato, com irrigação para manter a umidade do substrato durante os períodos de germinação das sementes e emergência das plântulas.

$\mathrm{O}$ delineamento experimental foi o de blocos casualizados, com os tratamentos distribuídos em esquema fatorial 3 x 6, com quatro repetições em parcelas formadas por seis tubetes. O primeiro fator correspondeu às fontes de material orgânico (esterco bovino, húmus de minhoca e cama de peru) e o segundo, suas proporções $(0,20,40,60$, 80 e $100 \%$ ) adicionadas ao substrato artificial (BioPlantcafé). No estádio "orelha-de-onça" realizou-se a repicagem das plântulas normais e uniformes para tubetes cônicos com capacidade de $120 \mathrm{~mL}$. A fertilização dos substratos foi realizada aplicando, em mistura homogênea, $1 \mathrm{~g}$ por recipiente do fertilizante comercial de liberação gradual, osmocote ${ }^{\circledR}$, fórmula NPK 15-09-12. Em seguida, as mudas foram transferidas para o viveiro coberto com tela sombrite com $50 \%$ de redução da capacidade luminosa, posicionada a $2 \mathrm{~m}$ acima dos tubetes e nas laterais para evitar a incidência direta do sol sobre as mudas.

Para avaliação do desenvolvimento das mudas, foram analisadas as seguintes características: altura da 
DIAS, R. et al.

planta, diâmetro de caule, número de pares de folhas por planta, área foliar e as massas secas da parte aérea e do sistema radicular. Estas características foram analisadas 95 dias após o transplante ao tubete. A altura da planta compreendeu a distância entre a região do colo e a gema terminal do ramo principal, determinando-se também na região do colo o diâmetro do caule. A área foliar foi estimada pela fórmula proposta por Barros et al. (1973) e Huerta (1962), confirmada por Gomide et al. (1977). As massas secas da parte área e do sistema radicular foram obtidas após lavagem do sistema radicular em água corrente e posterior separação das partes (aérea e radicular) com um corte na altura do colo. As partes distintas foram submetidas à secagem em estufa com circulação forçada de ar a $60^{\circ} \mathrm{C}$ até peso constante.

As características estudadas foram submetidas à análise de variância, seguida pelo teste de Tukey para comparações entre médias de substratos e regressão polinomial para determinação da proporção de material orgânico (BANZATTO \& KRONKA, 2006). As análises foram executadas pelo programa SISVAR versão 5.0 (FERREIRA, 2003), e em todos os testes foi utilizado $\alpha=0,05$ como valor de significância.

\section{RESULTADOS E DISCUSSÃO}

As fontes de material orgânico acrescentadas em proporções de até $40 \%$ do volume total do substrato artificial não alteram significativamente o número de pares de folhas, o diâmetro de caule e a altura das mudas do cafeeiro (Tabela 1). Contudo, o húmus de minhoca e o esterco bovino, ambos na proporção de $40 \%$, aumentaram a área foliar das mudas de cafeeiro em relação à cama de peru.

O número de pares de folhas foi semelhante entre as fontes de material orgânico na proporção de $60 \%$ estando entre 4 e 5,5 (Tabela 1). Mas, nesta mesma proporção de húmus de minhoca, houve acréscimo do diâmetro do caule, da altura da muda e da área foliar, ainda que para a área foliar o húmus não tenha diferido do esterco bovino. Em proporções superiores a $80 \%$, o húmus de minhoca não diferiu ou foi superior ao esterco bovino e a cama de peru nas características analisadas (Tabela 1), sendo que com o uso exclusivo de esterco bovino (100\%) as mudas de cafeeiro morreram.

De maneira geral, o aumento da proporção do material orgânico no substrato artificial reduziu a área foliar (Figura 1a), número de pares de folhas (Figura 1b), diâmetro do caule (Figura 1c) e altura da planta (Figura 1d), com queda mais acentuada quando a fonte foi $o$ esterco bovino.

No entanto, até $30 \%$ de esterco bovino adicionado ao substrato artificial não houve comprometimento das mudas de cafeeiro. O incremento da área foliar foi concomitante com o aumento da proporção de húmus de minhoca adicionado ao substrato artificial, sendo esta expansão ocorrida à taxa de $0,07 \mathrm{~cm}^{2}$ a cada $1 \%$ de húmus adicionado (Figura 1a). A cama de peru foi a fonte mais

Tabela 1 - Médias de área foliar, número de pares de folhas, diâmetro de caule e altura de mudas de cafeeiro submetidas a fontes de material orgânico e suas proporções no substrato artificial. UFU, Uberlândia-MG, 2006.

\begin{tabular}{|c|c|c|c|c|c|}
\hline \multirow[b]{3}{*}{ Fonte de material orgânico } & \multicolumn{5}{|c|}{ Proporção $(\%)^{1}$} \\
\hline & 20 & 40 & 60 & 80 & 100 \\
\hline & \multicolumn{5}{|c|}{ Área foliar $\left(\mathrm{cm}^{2}\right)$} \\
\hline Esterco bovino & $28,4 \mathrm{a}$ & $29,5 \mathrm{ab}$ & $29,3 \mathrm{a}$ & $17,5 \mathrm{~b}$ & $0,00 \mathrm{c}$ \\
\hline Húmus de minhoca & $31,1 \mathrm{a}$ & $33,0 \mathrm{a}$ & $32,7 \mathrm{a}$ & $35,8 \mathrm{a}$ & $35,2 \mathrm{a}$ \\
\hline \multirow[t]{2}{*}{ Cama de peru } & $26,3 \mathrm{a}$ & $25,8 \mathrm{~b}$ & $19,4 \mathrm{~b}$ & $20,0 \mathrm{~b}$ & $21,7 \mathrm{~b}$ \\
\hline & \multicolumn{5}{|c|}{ Número de pares de folhas } \\
\hline Esterco bovino & $5,33 \mathrm{a}$ & $5,25 \mathrm{a}$ & $4,63 \mathrm{a}$ & $4,28 \mathrm{~b}$ & $0,00 \mathrm{c}$ \\
\hline Húmus de minhoca & $5,66 \mathrm{a}$ & $5,34 \mathrm{a}$ & $5,19 \mathrm{a}$ & $5,53 \mathrm{a}$ & $5,44 \mathrm{a}$ \\
\hline \multirow[t]{2}{*}{ Cama de peru } & $4,78 \mathrm{a}$ & $4,78 \mathrm{a}$ & $4,38 \mathrm{a}$ & $4,52 \mathrm{~b}$ & $3,90 \mathrm{~b}$ \\
\hline & \multicolumn{5}{|c|}{ Diâmetro do caule $(\mathrm{cm})$} \\
\hline Esterco bovino & $2,94 \mathrm{a}$ & $2,81 \mathrm{a}$ & $2,54 \mathrm{~b}$ & $2,36 \mathrm{~b}$ & $0,00 \mathrm{c}$ \\
\hline Húmus de minhoca & $3,17 \mathrm{a}$ & $3,04 \mathrm{a}$ & $3,10 \mathrm{a}$ & $2,91 \mathrm{a}$ & $2,86 \mathrm{a}$ \\
\hline \multirow[t]{2}{*}{ Cama de peru } & $3,19 \mathrm{a}$ & $3,02 \mathrm{a}$ & $2,74 \mathrm{~b}$ & $2,72 \mathrm{a}$ & $2,43 \mathrm{~b}$ \\
\hline & \multicolumn{5}{|c|}{ Altura $(\mathrm{cm})$} \\
\hline Esterco bovino & $15,4 \mathrm{a}$ & $15,1 \mathrm{a}$ & $14,3 \mathrm{~b}$ & $11,7 \mathrm{~b}$ & $0,00 \mathrm{c}$ \\
\hline Húmus de minhoca & $16,4 \mathrm{a}$ & $17,1 \mathrm{a}$ & $17,1 \mathrm{a}$ & $16,3 \mathrm{a}$ & $16,4 \mathrm{a}$ \\
\hline Cama de peru & $15,8 \mathrm{a}$ & $15,3 \mathrm{a}$ & $13,6 \mathrm{~b}$ & $12,6 \mathrm{~b}$ & $11,0 \mathrm{~b}$ \\
\hline
\end{tabular}

${ }^{1}$ Médias seguidas por letras distintas na coluna, para cada característica estudada, diferem pelo teste de Tukey a 0,05 de significância. 
(a)
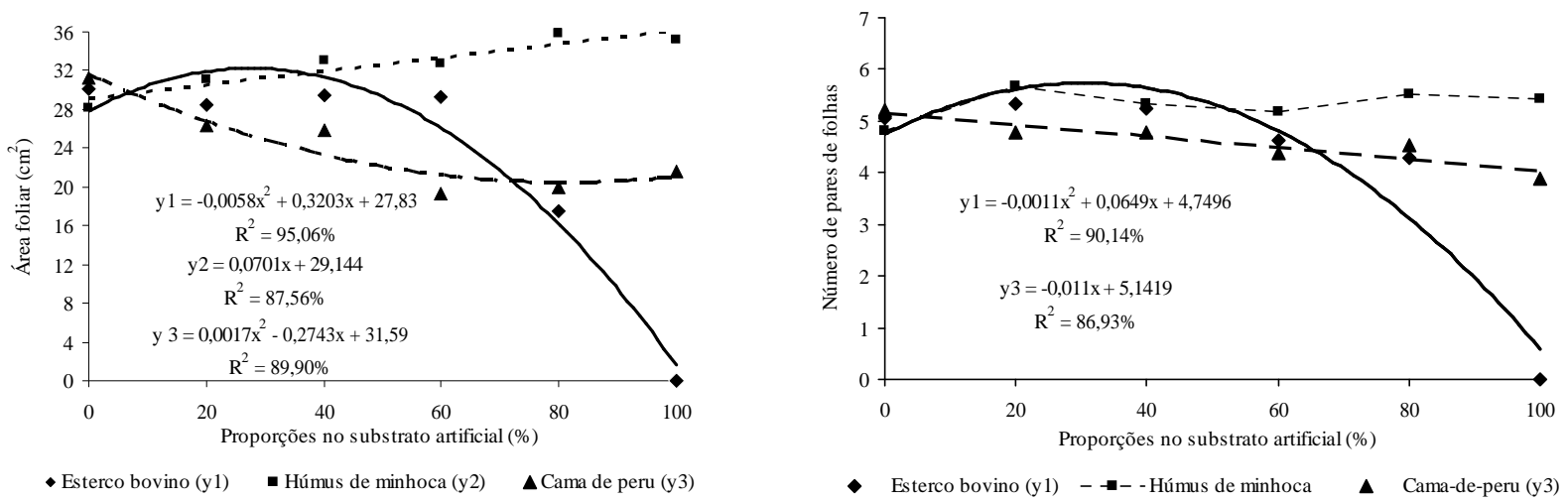

(c)

(d)
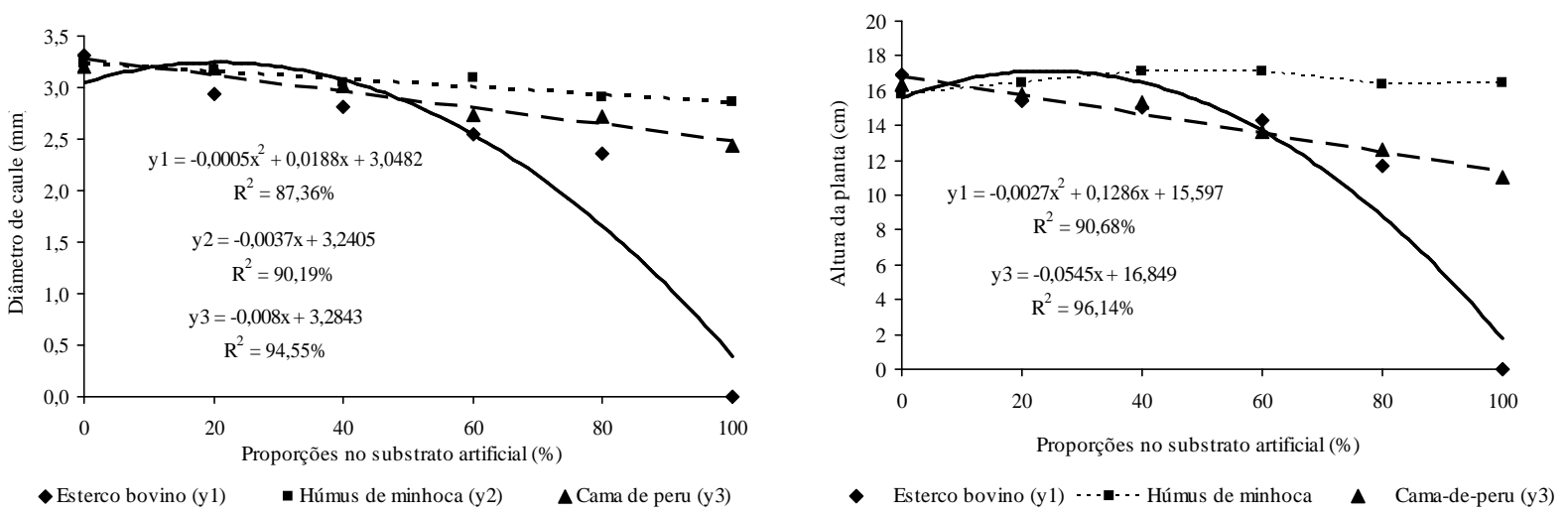

Figura 1 - Alterações nos valores de área foliar (a), número de pares de folhas (b), diâmetro de caule (c) e altura das mudas (d) para esterco bovino, húmus de minhoca e cama de peru em função das proporções no substrato artificial. UFU, Uberlândia-MG, 2006.

comprometedora da área foliar, do número de pares de folhas, do diâmetro e da altura das mudas do cafeeiro (Figura 1). Andrade Neto et al. (1999), por sua vez, avaliando substratos alternativos para mudas de cafeeiro em tubetes verificaram que, de maneira geral, a melhor fonte de matéria orgânica para altura de plantas foi o esterco de curral na proporção de $80 \%$, quando adubado com osmocote, obtendo, em média, plantas com altura máxima de $20,03 \mathrm{~cm}$. Toledo (1992), em estudo com diferentes substratos para a formação de mudas de laranjeira, encontrou maiores valores de altura e diâmetro das mudas para a mistura de $30 \%$ de solo, $40 \%$ de areia e $30 \%$ de húmus de minhoca, justificando a superioridade desse substrato aos benefícios do componente húmus.

Considerando a massa seca da parte aérea e da raiz das mudas de cafeeiro, a fonte de material orgânico que favoreceu o acúmulo de massa foi o húmus de minhoca, principalmente quando adicionado em maiores proporções
(Tabela 2). O húmus modificou a massa seca da parte área quando adicionado em proporções acima de $40 \%$, contudo essa modificação foi observada para o sistema radicular apenas em proporções acima de $80 \%$. Diferente das outras características estudadas (Tabela 1), a partir de $60 \%$ de adição de material orgânico, o húmus de minhoca foi sempre superior às demais fontes para massas secas de parte aérea e raiz (Tabela 2).

A massa seca da parte aérea foi significativamente influenciada pelo aumento na proporção de húmus de minhoca (Figura 2a), com incremento da ordem de 0,0026 g para cada $1 \%$ suplementado ao substrato artificial, atingindo $1,35 \mathrm{~g}$ por planta com seu uso exclusivo (100\%). Esse mesmo acréscimo não foi constatado para a massa seca do sistema radicular (Figura $2 b$ ) onde a proporção de húmus não influenciou esta característica. Até aproximadamente $30 \%$ de esterco de bovino (ponto máximo da curva) há aumento da massa seca da parte aérea (Figura 
Tabela 2 - Médias de massa seca da parte aérea e do sistema radicular de mudas de cafeeiro submetidas a fontes distintas de material orgânico e proporções no substrato artificial. UFU, Uberlândia-MG, 2007.

\begin{tabular}{lccccc}
\hline & \multicolumn{5}{c}{ Proporção $(\%)^{1}$} \\
\cline { 2 - 6 } & 20 & 40 & 60 & 80 & 100 \\
\hline Fonte de material orgânico & \multicolumn{7}{c}{ Massa seca da parte aérea $(\mathrm{g})$} \\
\hline Esterco bovino & $1,04 \mathrm{a}$ & $1,04 \mathrm{ab}$ & $0,94 \mathrm{~b}$ & $0,66 \mathrm{~b}$ & $0,00 \mathrm{c}$ \\
Húmus de minhoca & $1,18 \mathrm{a}$ & $1,24 \mathrm{a}$ & $1,28 \mathrm{a}$ & $1,23 \mathrm{a}$ & $1,35 \mathrm{a}$ \\
Cama de peru & $0,97 \mathrm{a}$ & $0,91 \mathrm{~b}$ & $0,77 \mathrm{~b}$ & $0,73 \mathrm{~b}$ & $0,60 \mathrm{~b}$ \\
\hline & \multicolumn{5}{c}{ Massa seca de raiz $(\mathrm{g})$} \\
\hline Esterco bovino & $0,43 \mathrm{a}$ & $0,39 \mathrm{a}$ & $0,37 \mathrm{a}$ & $0,27 \mathrm{~b}$ & $0,00 \mathrm{c}$ \\
Húmus de minhoca & $0,57 \mathrm{a}$ & $0,52 \mathrm{a}$ & $0,51 \mathrm{a}$ & $0,50 \mathrm{a}$ & $0,50 \mathrm{a}$ \\
Cama de peru & $0,53 \mathrm{a}$ & $0,45 \mathrm{a}$ & $0,38 \mathrm{a}$ & $0,34 \mathrm{~b}$ & $0,25 \mathrm{~b}$ \\
\hline
\end{tabular}

${ }^{1}$ Médias seguidas por letras distintas na coluna, para cada característica estudada, diferem pelo teste de Tukey a 0,05 de significância.

(a)

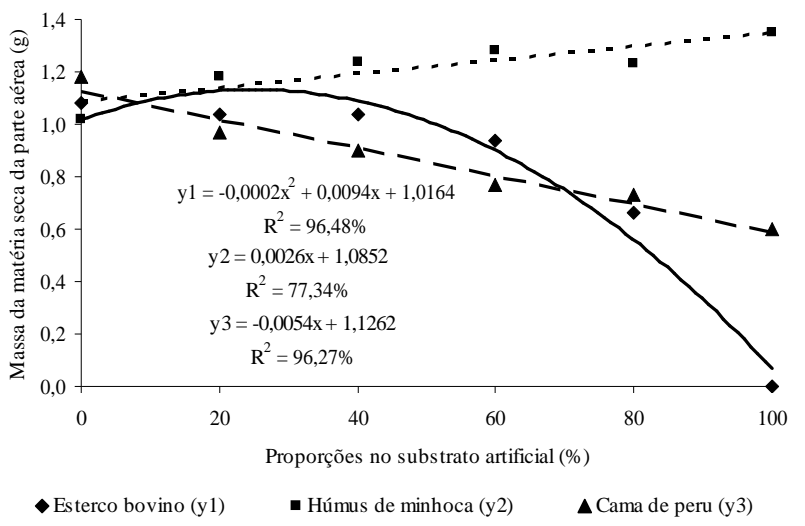

(b)

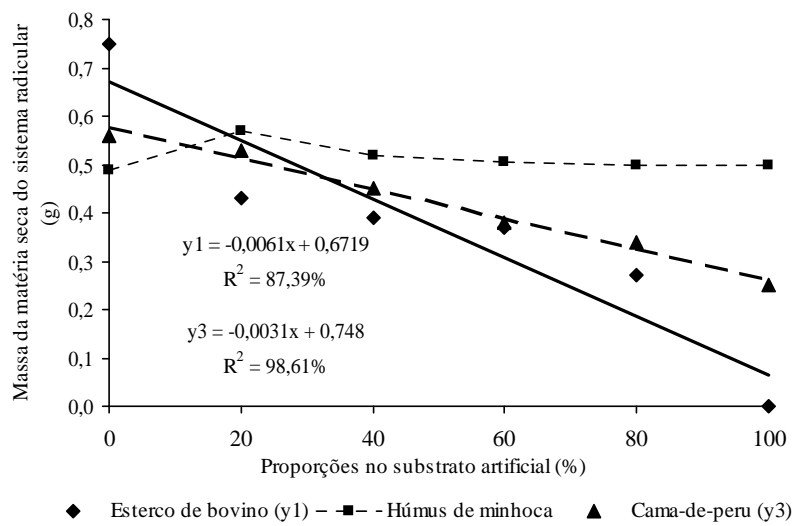

Figura 2 - Alteração nos valores de massa seca da parte aérea (a) e do sistema radicular (b) para esterco bovino, húmus de minhoca e cama de peru em função das proporções distintas de substrato artificial. UFU, Uberlândia-MG, 2007.

2a), com conseqüente comprometimento à medida que a proporção desta fonte orgânica é aumentada. Contudo, a maior conseqüência do esterco bovino é a redução da massa seca de raiz (Figura 2b). Acredita-se que o alto teor de $\mathrm{N}$ seja responsável pela melhoria na qualidade das mudas com o acréscimo de esterco bovino até doses próximas de $30 \%$. Além dessa proporção, esse alto teor, aliado a uma baixa relação $\mathrm{C} / \mathrm{N}$, prejudicou a qualidade das mudas, podendo ser a causa da morte dessas a uma proporção de $100 \%$ de esterco bovino.

Andrade Neto et al. (1999) constataram que a melhor fonte de matéria orgânica para a produção de massa seca da parte aérea é o esterco de curral na dose de $80 \%$ adubado com osmocote. O valor máximo estimado foi de 15,69 g, apresentando o mesmo efeito linear crescente. $\mathrm{O}$ húmus de minhoca também foi superior para essa característica em relação ao controle, com melhor resultado uma dose de $36 \%$ de húmus junto ao substrato. A cama de peru, em qualquer proporção reduziu as massas secas da parte aérea (Figura 2a) e do sistema radicular (Figura 2b).

Carvalho et al. (1978), em experimento com substratos para produção de mudas de cafeeiro em sacos plásticos, concluíram que o maior peso de matéria seca da parte aérea, quando se utilizou esterco bovino, ocorreu com a dose de $30 \%$ do mesmo no substrato adubado com superfosfato simples $\left(0,85 \mathrm{~kg}\right.$ de $\mathrm{P}_{2} \mathrm{O}_{5} \mathrm{~m}^{-3}$ de substrato), e quando se utilizou o húmus de minhoca na dose de $36,38 \%$, adubado com osmocote.

Theodoro et al. (1997) testaram diversas doses de húmus de minhoca, esterco de curral e composto orgânico na composição do substrato utilizado para a obtenção de mudas de cafeeiro e observaram que quando o húmus de 
minhoca foi utilizado na mesma dose do esterco de curral, não ocorreram variações significativas nos parâmetros avaliados e, portanto, não houve variação na qualidade das mudas obtidas.

\section{CONCLUSÕES}

O húmus de minhoca adicionado ao substrato artificial na proporção de $80 \%$ ou em uso exclusivo (100\%) acrescido de fertilizante de liberação gradual aumentou a área foliar das mudas de cafeeiro e, como conseqüência, proporcionou um acúmulo de massa seca tanto na parte aérea como no sistema radicular. O uso de esterco bovino acima de $30 \%$ e a cama de peru, também acrescidos de fertilizante de liberação gradual, não alterou ou reduziu as características vegetativas das mudas de cafeeiro diminuindo o acúmulo de massa seca.

\section{REFERÊNCIAS BIBLIOGRÁFICAS}

ANDRADE NETO, A.; MENDES, A. N. G.; GUIMARÃES, P. T. G. Avaliação de substratos alternativos e tipos de adubação para a produção de mudas de cafeeiro (Coffea arabica. L.) em tubetes. Ciência e Agrotecnologia, Lavras, v. 23, n. 2, p. 270-280, 1999.

\section{BANZATTO, D. A.; KRONKA, S. N. Experimentação agrícola. 4. ed. Jaboticabal: FUNEP, 2006. 237 p.}

BARROS, R. S.; MAESTRI, M.; VIEIRA, M.; BRAGAFILHO, L. J. Determinação de área de folhas do café (Coffea arabica L. cv. 'Bourbon Amarelo'). Revista Ceres, Viçosa, v. 20, n. 107, p. 44-52, 1973.

CARRIJO, O. A.; VIDAL, M. C.; REIS, N. V. B.; SOUZA, R. B.; MAKISHIMA, N. Produtividade do tomateiro em diferentes substratos e modelos de casas de vegetação. Horticultura Brasileira, Brasília, v. 22, n. 1, p. 5-9, 2004.

CARVALHO, M. M. de. Formação de mudas. Informativo Agropecuário, Belo Horizonte, v. 4, n. 44, p. 14-18, 1978.

CARVALHO, M. M.; DUARTE, G. de S.; RAMALHO, M. A. P. Efeito da decomposição de substrato, no desenvolvimento de mudas de cafeeiro (Coffea arabica L.) Ciência e Prática, Lavras, v. 2, n. 1, p. 20-34, 1978.

CUNHA, A. M.; CUNHA, G. M.; SARMENTO, R. A.; CUNHA, G. M.; AMARAL, J. F. T. Efeitos de diferentes substratos sobre o desenvolvimento de mudas de Acacia sp. Revista Árvore, Viçosa, v. 30, n. 2, p. 207-214, 2006.
FAGUNDES, N. B.; FIALHO, A. A. Produção de mudas de Eucalyptus. Boletim Técnico do Instituto Florestal, São Paulo, v. 40, n. 1, p. 237-245, 1986.

\section{FERREIRA, D. F. SISVAR 5.0 Sistema de Análises Estatísticas. Lavras: UFLA, 2003.}

FONSECA, T. G. Produção de mudas de hortaliças em substratos de diferentes composições com adição de $\mathbf{C O}_{2}$ na água de irrigação. 2001. 72 f. Dissertação (Mestrado em Agronomia) - Escola Superior de Agricultura "Luiz de Queiroz", Piracicaba, 2001.

FREITAS, T. A. S. de; BARROSO, D. G.; CARNEIRO, J. D. A.; PENCHEL, R. M.; FIGUEIREDO, F. A. M. M. A. Mudas de eucalipto produzidas a partir de miniestacas em diferentes recipientes e substratos. Revista Árvore, Viçosa, v. 30, n. 4, p. 519-528, 2006.

GOMIDE, M. B.; LEMOS, O. V.; TOURINO, D.; CARVALHO, M. M.; CARVALHO, J. G.; DUARTE, C. S. Comparação entre métodos de determinação de área foliar em cafeeiros Mundo Novo e Catuaí. Ciência e Prática, Lavras, v. 1, n. 2, p. 118-123, 1977.

GONÇALVES, J. L. M.; POGGIANI, F. Substratos para produção de mudas florestais. In: CONGRESSO LATINO AMERICANO DE CIÊNCIA DO SOLO, 13., 1996, Águas de Lindóia. Anais... Águas de Lindóia, 1996. CD-ROM.

GUIMARÃES, P. T. G.; CARVALHO, M. M. de; MENDES, A. N. G.; BARTHOLO, G. F. Produção de mudas de café: coeficientes técnicos da fase de viveiro. Informe Agropecuário, Belo Horizonte, v. 14, n. 162, p. 5$10,1989$.

HUERTA, S. A. Comparación de métodos de laboratorio y de campo para medir el area del cafeto. Cenicafé, Chinchina, v. 13, n. 1, p. 33-42, 1962.

LOPES, P. S. N. Propagação sexuada do maracujazeiro azedo (Passiflora edulis Sims f. favicarpa Deg.) em tubetes: efeito de adubação nitrogenada e substratos. 1996. 52 f. Dissertação (Mestrado em Fitotecnia) Universidade Federal de Lavras, Lavras, 1996.

MELLO, B. Estudos sobre produção de mudas de cafeeiro (Coffea arabica L.) em tubetes. 1999. 119 p. Tese (Doutorado em fitotecnia) - Universidade Federal de Lavras, Lavras, 1999. 
NEVES, J. C. L.; GOMES, J. M.; NOVAIS, R. F.

Fertilização mineral de mudas de eucalipto. In: BARROS,

N. F.; NOVAIS, R. F. Relação solo-eucalipto. Viçosa:

Folha de Viçosa, 1990. 330 p.

PASQUAL, M.; CHALFUN, N. N. J.; RAMOS, J. D.; VALE, M. R. do; SILVA, C. R. R. de. Fruticultura comercial: propagação de plantas frutíferas. Lavras: UFLA/FAEPE, 2001. 137 p.

POZZA, A. A. A.; MARTINEZ, H. E. P. M.; CAIXETA, S. L.; CARDOSO, A. A.; ZAMBOLIM, L.; POZZA, E. A. Influência da nutrição mineral na intensidade da manchade-olho-pardo em mudas de cafeeiro. Pesquisa
Agropecuária Brasileira, Brasília, v. 36, n. 1, p. 53-60, jan. 2001.

THEODORO, V. C. A.; CARVALHO, J. G.; ASSIS, M. P.; GUIMARÃES, R. J.; SILVA, E. B.; FERREIRA, L. Uso do vermicomposto na produção de mudas de cafeeiro (Coffea arabica L.). In: CONGRESSO BRASILEIRO DE PESQUISAS CAFEEIRAS, 23., 1997, Manhuaçu. Anais... Rio de Janeiro: IBG; GERCA, 1997. p. 164-166.

TOLEDO, A. R. M. Efeito de substratos na formação de mudas de laranjeira (Citrus sinensis) em vaso. 1992. $88 \mathrm{f}$. Dissertação (Mestrado em Fitotecnia) - Universidade Federal de Lavras, Lavras, 1992. 